\title{
Aspects of Human-Centered Design Application in Control Information Systems
}

\author{
Shekhovtsova Victoriya ${ }^{1}$ \\ Veretelnikov Dmytro ${ }^{2}$ \\ Lebediev Valentyn ${ }^{3}$
}

${ }^{1}$ Kharkiv National University of Radio Electronics, 14 Nauky Ave, KharkivUA-61166, Ukraine, viktoriia.shekhovtsova@nure.ua

${ }^{2}$ Kharkiv National University of Radio Electronics, 14 Nauky Ave, KharkivUA-61166,Ukraine, dmytro.veretelnikov@nure.ua

${ }^{3}$ Kharkiv National University of Radio Electronics, 14 Nauky Ave, KharkivUA-61166, Ukraine, lebedevvalen@gmail.com

\begin{abstract}
Principles, approaches and methodology of HumanCentered Design, set out in the ISO 9241-210 standard, give recommendations to developers according to the planning and implementation of information systems with interactive components. Analysis of the proposed rules and actions revealed the missing aspects, which, according to the authors, are essential for minimizing the influence of the human factor in information management systems.
\end{abstract}

Keywords: Human-Centered Design, human factor, design principles, usability.

\section{INTRODUCTION AND PROBLEM STATEMENT}

In the "man-technology-environment" system, the weak link is a man. His qualification, experience, ability and willingness to quickly adapt to changing technical and technological innovations and environmental factors do not fully guarantee the ideal result in the design and operation of both information management systems and other IT products.

For the preventive exclusion of the negative impact of the human factor, the methodology Human-Centered Design (hereinafter - HCD), the Scrum and Waterfall models are used. However, the problem is not solved only C. It is necessary to find out the missing aspects, the consideration of which will allow to reduce to zero the negative consequences of human factor.

\section{PROBLEM SOLUTION AND RESULTS}

ISO standard 9241-210. Planning and Implementation HCD highlights six design principles within Human-Centered Design [1]:

1. Design should be based on an accurate definition of users, their tasks and environment.

2. Users should be involved in design and development.

3. Design should be based on user feedback.

4. The process should be iterative.

5. The design addresses the whole user experience.

6. The team must be multidisciplinary.

The standard clearly distinguishes actions of the developer according to the HCD methodology [2]:

1. Identify required resources and suitable methods.

2. Determining how the above methods will be integrated with other development processes.

3. Identification of responsible.

4. Determination of communication channels and methods for resolving contradictions.
5. The time frames of individual stages of the HCD and their integration into overall development plan should be agreed.

As part of the usage context specification, ISO 9241210 recommends the following actions: [3]:

1. Identify the main user groups and stakeholders (stakeholders).

2. Define the goals and objectives of the above users and stakeholders.

3. Define the technical, organizational and physical environment.

This allows you to formulate product requirements in the following order:

1. Describe product requirements.

2. Resolve conflicts between different requirements.

3. Verify the quality of the stated requirements. Requirements must be:

- Formulated so that in the future the product can be tested in accordance with these requirements;

- Agreed with all interested parties;

- Holistic;

- Relevant and updated throughout the project's life cycle [4].

At the design stage of interaction, it is recommended:

1. Design user tasks, user-system interactions, as well as the interface.

2. Present in details project decisions.

3. Use user feedback to improve design decisions.

4. Deliver design solutions to those who will be involved in the development and implementation [3].

For a proper assessment of compliance with the requirements:

1. Get updated relevant user information.

2. Get feedback as for design weaknesses and strengths.

3. Establish criteria against which you will compare the current and next versions of the project.

In accordance with the obtained results, it is possible:

- invite future users to pass test of the developed information system to identify inaccuracies, missing elements or erroneous accents of the developer;

- listen to the opinion of competent experts with experience in the development and implementation of such products;

- carry out meticulous monitoring of critical situations, incidents and problematic delays, support calls, etc.

If necessary, you can make changes and repeat some of the stages of testing. But all this costs money and time. 
Therefore, sooner or later, the project team will have to stop and present their project to the customer.

Such theoretical approach, outlined in the standard, is abstract in nature and can be considered as a recommendation for action, but often cannot act as a standard of rules.

It should be noted that all principles, approaches and methodologies do not take into account the emotional-valuable aspect of users. Even at the stage of planning the implementation of requirements, it is necessary to anticipate a possible change in both the users themselves and their requirements.

The developer cannot foresee absolutely all the consequences of untimely, incorrect or completely wrong user actions. That is why, it is necessary to deliberately set "control points", to fix the slightest deviations from the logic of the process or fluctuations in the responses, user reactions.

\section{CONCLUSIONS}

All rules and principles work in conditions of their impeccable implementation. The human factor arises when the established algorithm of actions is not followed. Therefore, developers committed to the Human-Centered Design methodology need to focus on the person, as a source of error, and obviously provide ways to eliminate them.

\section{REFERENCES}

[1] ISO 9241-210:2019 Ergonomics of human-system interaction - Part 210: Human-centred design for interactive systems\& / https://www.iso.org/ru/standard/77520.html

[2] ГОСТ Р ИСО 9241-210-2016 Эргономика взаимодействия человексистема. Часть 210. Человеко-ориентированное проектирование интерактивных систем http://docs.cntd.ru/document/1200141127

[3] ISO 9241-210. Планирование и внедрение Human-Centered Design Usability https://habr.com/ru/post/258635/

[4] Top 4 Principles of Human-Centered Design Nick Babich https://uxplanet.org/top-4-principles-of-human-centered-design$5 \mathrm{e} 02751 \mathrm{e} 65 \mathrm{~b} 1$

[5] A Human-Centered Design Methodology to Enhance the Usability, Human Factors, and User Experience of Connected Health Systems: A Three-Phase https://www.ncbi.nlm.nih.gov/pmc/articles/PMC5374275/

Methodology.

[6] A lab of labs:methods and approaches for a human-centered design http://www.publishinglab.nl/wpcontent/uploads/2017/11/ALabofLabsWEB.pdf 